Primera versión recibida en: 31 mayo, 2018

Última versión recibida en: 29 septiembre, 2018

\title{
El empoderamiento de la gestión urbanística en la metrópolis de Barcelona (España), desde una perspectiva global
}

The empowerment of urban management in the metropolis of Barcelona (Spain), from a global perspective

Andreu Marfull Pujadas ${ }^{1}$

\section{Resumen}

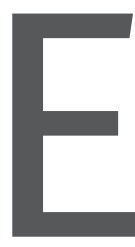

n este trabajo se explora la naturaleza de la desigual institucionalización del poder en la gestión urbana, a través de una doble exploración. Por un lado, se presenta el espacio de análisis en una coyuntura global, y por otro, se explora el caso de la metrópolis de Barcelona. La hipótesis de partida es que el empoderamiento público y social en la gestión urbana de la metrópolis de Barcelona requiere, antes de ser efectivo, de su encaje geopolítico internacional para participar del privilegio del plusvalor generado en una economía globalizada. El diseño de la investigación ahonda en la comprensión de una complicidad geopolítica y social en un orden desigual que cons-

1 Doctor en Geografía de la Universitat Autònoma de Barcelona especializado en planificación, gestión y valoración urbanística. Email: andreumarfull@gmail.com

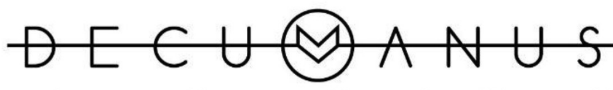

REVISTA INTERDISCIPLINARIA SOBRE ESTUDIOS URBANOS truye un sistema de ciudades desigual, y cómo se refleja esta situación en el caso de Barcelona. Mediante el contraste del análisis circular de los resultados se concluye que la hipótesis es afirmativa, pero con una particularidad. Se identifica el proceso de empoderamiento político y social de la gestión urbana y el rol activo del sector económico, pero a su vez se constata que la economía globalizada no está sujeta a un control político y social efectivo. Dicha situación se enmarca en el desigual equilibrio de poder observable en el orden económico internacional, que es el resultado de un proceso histórico caracterizado por una competencia desigual entre los Estados del mundo.

Palabras Clave:

Barcelona, gestión urbanística, empoderamiento, institucionalización.

\section{Abstract:}

This paper explores the nature of the unequal institutionalization of power 
in urban management, through a double exploration. On the one hand, the analysis space is presented in a global context, and on the other, the case of the metropolis of Barcelona is explored. The starting hypothesis is that the public and social empowerment in the urban management of the metropolis of Barcelona requires, before being effective, its international geopolitical accommodation to participate in the privilege of the added value generated in a globalized economy. The design of the investigation deepens the understanding of a geopolitical and social complicity in an unequal order that builds an unequal system of cities, and how this situation is reflected in the case of Barcelona. By contrasting the circular analysis of the results, it is concluded that the hypothesis is affirmative, but with a particularity. It identifies the process of political and social empowerment of urban management and the active role of the economic sector, but at the same time it is found that the globalized economy is not subject to effective political and social control. This situation is framed by the unequal balance of power observable in the international economic order, which is the result of a historical process characterized by unequal competition among the states of the world.

\section{Keywords:}

Barcelona, urban management, empowerment, institutionalization.

\section{Introducción: presentación, hipótesis y diseño de la investigación}

\subsection{Presentación: la desigual institucionalización del poder en la gestión urbana}

Existen ciudades donde las desigualdades no representan un problema relevante, y existen ciudades donde se trata de un problema fundamental al que se enfrentan las políticas sociales y económicas dirigidas por la Administración Pública. En las primeras, por lo general, se identifica la presencia de una gestión institucionalizada efectiva, y en las segundas, no.

Sin embargo, la exploración de la problemática de las desigualdades estructurales que se identifican en todas las ciudades no forma parte del análisis crítico común o habitual, es decir, del debate de dominio público. En su lugar, cada ciudad tiende a construir su propio relato, en el que se ensalzan los retos asumidos (resueltos o no) pero dejando en un segundo plano la cuestión del estado de competencia global como causa y efecto del desigual reparto de la riqueza entre las ciudades y en las ciudades mismas. De este modo, el proceso de urbanización sigue su curso, creando un relato de éxitos y fracasos a medias que ocultan o evitan una situación problemática que está relacionada con una norma o regla global imperfecta: la desigualdad del poder institucionalizado que crea capital acumulativo y compite por él.

Un análisis racional de las grandes metrópolis que incorpore la interconexión entre la historia de su proceso 
de institucionalización urbana y el proceso histórico asociado que las impulsa a su incesante desarrollo, refleja de qué modo cada lugar tiende a la adaptación (especialización, rol o rostro) de su actividad al mercado mundial, y de qué modo se ve beneficiado o perjudicado por ello. Pero, como se ha indicado, estos trabajos no son habituales y no suelen ahondar en la desigualdad del poder, en especial cuando se trata de estudios que afectan a ciudades beneficiadas por el desigual reparto de la riqueza a escala global. En su lugar, se fomenta un ideal cosmopolita universal que refleja las ventajas de la desigualdad evitando su relación con las desventajas que lo alimentan. El caso de la metrópolis de Barcelona, en la medida que ha promovido y difundido la idea de un modelo exitoso a escala global sin ahondar en las causas externas asociadas a la historia geopolítica del poder, sería apropiado para observar esta relación causal. Pero, paralelamente, al tratarse de un caso caracterizado por una institucionalización formal de los poderes económicos en el Estado y, en una segunda instancia, en la gestión de la ciudad, su análisis permite observar de qué modo (y hasta qué punto) participa del beneficio global.

\subsection{Hipótesis: el encaje social barcelonés en una economía globalizada}

La hipótesis de trabajo, orientada a profundizar en la naturaleza institucional de la gestión urbana, se plantea del siguiente modo: "El empoderamiento público y social en la gestión urbana de la metrópolis de Barcelona requiere, antes de ser efectivo, de su encaje geopolítico internacional para participar del privilegio del plusvalor generado en una economía global".

\subsection{Diseño de la investigación: ahondar en la comprensión de una complicidad geopolítica y social en un orden desigual que construye un sistema de ciudades desigual}

Para ahondar en la base geopolítica del aparente éxito barcelonés es necesario enmarcar su estudio en una contextualización histórica, crítica y racional del proceso de internacionalización de una economía basada en la creación de plusvalías por el estímulo de la competencia, que enlace con los patrones o modelos de gestión urbana asociados. En esta línea, se diseña un proceso de investigación orientado a la comprensión del proceso de empoderamiento económico de la gestión urbanística en la metrópolis, en especial a lo largo de los siglos XX y XXI, dejando el resto de su desarrollo a futuros debates planteados en su conclusión.

Para desarrollar la hipótesis de trabajo se propone ahondar en la comprensión de las complicidades inherentes entre un orden geopolítico internacional desigual (donde impera la lógica de una economía globalizada en competencia) y el empoderamiento público y social en la gestión urbana de Barcelona (donde no se identifica esta complicidad). Con esta finalidad, se realiza la siguiente secuencia de temas a explorar:

1. Análisis conceptual (I): la narrativa académica del desarrollo desigual observable en las aglomeraciones urbanas. 
2. Análisis conceptual (II): la narrativa jurídica y empresarial del Derecho Internacional.

3. Desarrollo práctico (I): el contraste entre la evolución del orden estatal e internacional institucionalizado y el proceso de regulación del orden legal urbanístico de aplicación en Barcelona.

4. Desarrollo práctico (II): el contraste entre la evolución del control ciudadano del territorio y el control político y económico asociado, en el Área Metropolitana de Barcelona.

El marco conceptual propuesto abor$\mathrm{da}$, en una primera instancia, el contraste entre dos relatos paralelos, que hablan por un lado del desarrollo geográfico desigual en la producción del espacio (Harvey, 2014) y por otro, de la narrativa de la presencia de coaliciones de poder en la gestión urbana de Barcelona (Casellas, 2016). En una segunda instancia se explora, desde un punto de vista jurídico e institucional, la naturaleza del derecho internacional (Casado Raigón, 2017; Pastor Ridruejo, 2017; Naciones Unidas, 2011), con la finalidad de discernir cuál es el orden económico que ampara y cómo se traslada a la planificación urbana y territorial. En conjunto, esta doble introspección permite establecer las relaciones de causalidad básicas para discernir de un modo racional los temas de interés a explorar en los dos apartados del desarrollo práctico.

El espacio a desarrollar se orienta a profundizar la comprensión del complejo legal e institucional, formal e informal, global y local, que pauta la dinámica evolutiva de la metrópolis de Barcelona. De este modo, una vez establecidas sus conexiones e identifi- cadas las evidencias de sus relaciones de afinidad, se ahonda en la naturaleza del empoderamiento público y social de la gestión urbana en Barcelona para, a continuación, dar una respuesta a la hipótesis de trabajo o investigación.

Finalmente, en un último apartado se desarrolla la discusión que plantean dichos resultados, se da una respuesta a la hipótesis de trabajo y se exponen las principales conclusiones que ofrece.

\section{Análisis conceptual: narrativas contrapuestas sobre el empoderamiento del orden urbano y territorial}

Como criterio general, esta investigación parte de la constatación de que coexisten, principalmente, dos narrativas paralelas que ahondan en la implementación de unos poderes económicos en la dinámica de las ciudades: a) las narrativas teóricas, que suelen imaginarse en espacios concretos pero que tienden a trasladar su exploración práctica a trabajos futuros que no suelen desarrollarse; y b) las narrativas prácticas, que se refieren a casuísticas particulares o bien a ciudades complejas, que tienden a explorar el impacto económico global a través de debates públicos normalizados por la sociedad, sin ahondar en el contenido crítico o el espacio teórico que ofrecen las narrativas teóricas. Dichas narrativas participan del debate académico y tienen la capacidad de trasladar parte de su contenido al sector político, que las incorpora sucintamente en el debate público, pero por lo general no participan del debate jurídico y empresarial relacionado, 
que desarrolla sus propios relatos. El relato del derecho -social y empresarial- que describe las relaciones de poder a escala internacional y tiene su reflejo en las distintas soluciones espaciales que los Estados y sus ciudades ofrecen, se sitúa en un espacio inexplorado. Se manifiesta, de este modo, una diversidad narrativa que conviene entretejer para profundizar en la cuestión principal que aborda esta investigación.

\subsection{Análisis conceptual (I): la narrativa académica del desarrollo desigual observable en las aglomeraciones urbanas}

El desarrollo desigual del paisaje urbano, observado en una escala planetaria, expresa un constructo funcional vinculado al desarrollo del mercado económico (Florida, 2009), en el cual unas pocas ciudades se ven beneficiadas por ello, siendo estas mismas las que concentran el PIB mundial y generan el mayor consumo de recursos (capital en la forma de bienes, servicios, energía, etcétera) y residuos (onU-Hábitat, 2016, pp. 16, 145, 165). Este planteamiento representa un desafio a las propias dinámicas de la agenda global dirigida por los Estados y las organizaciones internacionales, pero no forma parte del debate público normalizado. El debate ha sido promovido desde el seno de las Naciones Unidas (2017), pero no se ha inserido en el debate de la agenda global en la proporción de su importancia relativa. ${ }^{2}$ En su lu-

2 En el marco de las Naciones Unidas, a lo largo de los años 1976, 1996 y 2016 se han celebrado tres conferencias de alto nivel enfocadas en la problemática de los asentamientos urbanos. La finalidad

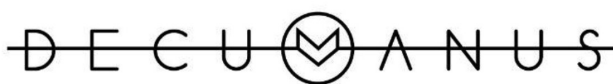

REVISTA INTERDISCIPLINARIA SOBRE ESTUDIOS URBANOS gar, desde distintos ámbitos aparecen espacios de reflexión y conocimiento que fomentan su comprensión y paulatinamente tienden a formar parte del debate académico internacional. David Harvey (2014) presenta esta realidad como parte de una problemática mayor, que la hace responsable de los desarrollos geográficos desiguales a escala global: las dinámicas del capitalismo acumulativo e inestable, capaces de crear valor añadido a costa de sucesivos procesos de devaluación que pasan a ser coyunturales al sistema. Pero resalta que, precisamente por este carácter incómodo, se trata de una realidad ignorada. Según Harvey (2014, pp. 161-161) "La ciudad capitalista constituye el punto álgido del intento del capital de mostrarse civilizado y de representar las más sublimes aspiraciones humanas", mientras que (p. 160): “Los desarrollos geográ-

de estas conferencias es promover acciones conjuntas a escala global para tratar la problemática emergente del crecimiento de las ciudades, en especial en los países en vías de desarrollo. En cada una de ellas se aprueba una declaración: 1a.) 1976 - Declaración sobre los Asentamientos Humanos, acordada en la Conferencia de las Naciones Unidas sobre los Asentamientos Humanos, celebrada en Vancouver (Canadá) entre los días 31 de mayo y 11 de junio de 1976; 2a.) 1996 - Declaración de Estambul sobre los Asentamientos Humanos, acordada en la Conferencia de las Naciones Unidas sobre los Asentamientos Humanos, celebrada en Estambul (Turquía) entre los días 3 y 14 de junio de 1996; y 3a.) 2016 - Declaración de Quito sobre ciudades y asentamientos humanos sostenibles para todos, acordada en la Conferencia de las Naciones Unidas sobre la Vivienda y el Desarrollo Urbano Sostenible (Hábitat III), celebrada en Quito (Ecuador) entre los días 17 y 20 de octubre de 2016. La conferencia y los acuerdos de 1976 se identifican como Hábitat I, la de 1996 como Agenda Hábitat o Hábitat II y la de 2016 como Nueva Agenda Urbana o Hábitat III. De este modo se resalta el seguimiento del proceso de urbanización global bajo el concepto de "hábitat" diferenciando tres etapas principales. 
ficos desiguales enmascaran convenientemente la auténtica naturaleza del capital. La esperanza puede mantenerse eternamente, porque siempre hay alguna localidad, región o zona afortunada, en la que las cosas van bien mientras que a su alrededor todo son calamidades".

Harvey $(2014$, p. 161) resalta que: "El desarrollo geográfico desigual sirve, por encima de todo, para desplazar los fallos sistémicos del capital de un lugar a otro". Pero su análisis incorpora una lectura paralela, que racionaliza la dinámica del movimiento del capital en continua expansión. Harvey complementa dicha reflexión con la identificación del papel de los Estados capitalistas en la configuración espacial del uso del capital, así como de las alianzas, siempre coyunturales y por lo tanto volátiles, que se generan entre ellos.

El Estado capitalista aplica en general políticas favorables a las empresas, aunque templadas por las ideologías dominantes y las innumerables y divergentes presiones sociales ejercidas por sus ciudadanos organizados; pero también trata de racionalizar y usar las fuerzas del capital para reforzar sus propios poderes de gubernamentalidad sobre poblaciones potencialmente reacias, al mismo tiempo que aumenta su propia riqueza, poder y estatus en un sistema interestatal muy competitivo. [...] El tipo de racionalidad típicamente impuesto por el Estado queda ilustrado por sus prácticas de planificación urbana y regional. Esas intervenciones e inversiones estatales intentan contener las consecuencias acaso caóticas del desarrollo de un mercado desregulado (Harvey, 2014, pp. 158-159).

Es decir, Harvey identifica un contrapeso en las prácticas desreguladas que se vislumbran a nivel internacional y las prácticas reguladas que en determinados Estados adoptan la forma de una planificación urbana y territorial coordinada y efectiva. Y esta cuestión es de interés en esta investigación, en la medida que la narrativa del proceso de identificación del rol del sector económico en la planificación metropolitana de Barcelona relata la transición de un Estado caracterizado por un desarrollo urbano caótico a otro más racional. Se trata, por tanto, de un caso que incluye la transición de un espacio desregulado a otro regulado, donde el rol o identidad del sector (o poder) económico adquiere un rostro visible y reconocido. $Y$ dicha transición no es casual, ya que va acompañada de una transición geopolítica estructural del Estado español: del paso de una dictadura militar integrada en el espacio capitalista a una democracia que mantiene este modelo económico, pero se integra en una alianza europea privilegiada.

A raíz del reconocimiento internacional que Barcelona adquiere con motivo de los Juegos Olímpicos de 1992, el urbanismo barcelonés es presentado al mundo como un ejemplo de los beneficios que conlleva integrarse a un modelo democrático capaz de capitalizar el Estado y dotarlo de una función social. De este modo, coincidiendo con el desmantelamiento de la Unión de Repúblicas Socialistas Soviéticas (URSS) en 1991 y la implementación generalizada del régimen capitalista, la ciudad democrática y capitalista barcelonesa se eri- 
ge como un modelo que pueden seguir otras ciudades del mundo. Antònia Casellas identifica esta coyuntura utilizando el análisis crítico de David Harvey, aportando a su vez el relato normalizado que los sectores académico, técnico y político han construido alrededor del llamado "Modelo Barcelona" a partir de la década de 1990. En dicho trabajo:

Se analiza por qué y cómo Barcelona, a pesar de haber presentado una imagen de política local progresista, no ha escapado a una transformación paulatina de su política urbana, a través de la cual el sector público ha reorientado su enfoque de gestión y redistribución social iniciada en los años ochenta, hacia una política urbana dominada por intereses de promoción económica y plusvalías del suelo (Casellas, p. 58).

En el proceso de reconocimiento del sector económico en la gestión urbana se identifican cuatro etapas principales, que tienen su punto de partida en la implantación del sistema democrático en 1978 (Casellas). En la primera etapa resalta el año 1979 como el instante de creación del primer ayuntamiento en un sistema democrático y su vocación de atender los desafios sociales generados por una urbanización caótica anterior. En la segunda, destaca el 1988 como el instante en que se crea la agencia público-privada que construye la infraestructura olímpica en la ciudad y el aprendizaje que tiene lugar entre ambos sectores. La tercera, sitúa la segunda mitad de la década de 1990 como una etapa avanzada del desarrollo urbano asociado a la atracción de capital inversor, junto con la difusión de su imagen asociada. Y la cuarta, resalta el 2010 como el instante en que se crea el Área Metropolitana de Barcelona, trasladando la imagen de la ciudad a su contexto metropolitano, pero orientando su promoción a la expansión del desarrollo promocional y económico de la urbe. Mediante una lectura transversal de su contenido, se identifica claramente el proceso de introducción racional del sector económico en la gestión urbana de la ciudad, a través de coaliciones de poder. Asimismo, el trabajo de Casellas expresa el descontento público que los sectores político y social manifiestan ante la deriva especulativa de la gestión urbana, cuestionando implícitamente el reparto de la riqueza generada y la función social del urbanismo. De este modo, participa de un relato normalizado que identifica al periodo franquista como una etapa oscura sin orden ni control, con un desarrollo de la ciudad informal, pero no se ahonda en el modo en que el sector económico participa en las estructuras del Estado español, reflejando a su vez apuntes a su estratégico encaje internacional. En su lugar, y coincidiendo con la narrativa académica barcelonesa normalizada (Benach, 2014; Borja, 2010; De Solà-Morales, 2008; Montaner, 2013; etcétera) se traslada la atención a una demanda política y social que forma parte del debate público: la voluntad de un mayor beneficio social y una mayor eficiencia en el modelo de desarrollo y gobernanza de la ciudad, para el justo beneficio de la ciudadanía.

Harvey expone el pulso entre los intereses de un régimen económico globalizado y los Estados, que requieren dotar dicha dinámica de una función social, mientras que Casellas expresa de qué modo la sociedad civil y el esta- 
mento político, en el caso de Barcelona, lidian con ella.

\subsection{Análisis conceptual (II): la narrativa jurídica y empresarial del derecho internacional}

El análisis de la narrativa jurídica y empresarial sobre el derecho internacional aclara la naturaleza del rol de las políticas estatales que interceden entre una economía globalizada y la gestión de las ciudades, ampliando el significado de la aportación de Harvey (2014). Del mismo modo, aclara la transición de un orden o desarrollismo estatal caracterizado por su función social entre las décadas de 1950 y 1980, a un orden alterado por una economía globalizada a partir de la década de 1990, aportando contenido para la comprensión del modo en que esta transición se efectúa en Barcelona. Para introducir su análisis, se realiza una introspección sucinta al significado de la existencia del derecho y el orden económico internacionales para, en una instancia posterior, presentar la narrativa empresarial que se enmarca en el derecho internacional.

En primer lugar, una cuestión capital. ¿Existe un derecho internacional? Existe un orden fundamental entre los Estados que son soberanos y se deben a un orden internacional implícito en el consenso, la costumbre y, sobre todo, los tratados internacionales. Esta interpretación forma parte del lenguaje jurídico internacional, que reconoce una cuestión tan fundamental como el hecho de que existe una sociedad internacional contemporánea que está afectada, dividida, en función del distinto poder político de los Estados entre sí (Casado

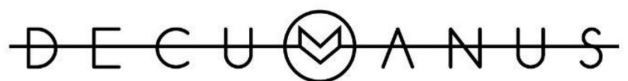

REVISTA INTERDISCIPLINARIA SOBRE ESTUDIOS URBANOS
Raigón, p. 70): "lo que se percibe, por ejemplo, en el status privilegiado que las grandes potencias poseen en ciertas organizaciones internacionales, como la onU o la Unión Europea" (Ibídem, p. 71). Bajo esta perspectiva, aquello que se considera derecho u orden internacional se enmarca en un complejo espacio de tratados, consensos y organizaciones internacionales que representan a una cooperación institucionalizada de ámbito universal. Las Naciones Unidas, por ejemplo, sería una Organización universal de cooperación política general (Pastor Ridruejo, p. 737). Sin embargo, pese a la fundación de las Naciones Unidas en 1945, a lo largo de la segunda mitad del siglo XX se normaliza una compleja estructura de organizaciones regionales internacionales para la defensa de los intereses económicos, estratégicos o de seguridad. De hecho, tal y como resalta Rafael Casado Raigón (p. 60 ), la mayoría de las organizaciones regionales "persiguen unos fines específi$\cos y$, particularmente, de carácter económico", resaltando el carácter singular de la Unión Europea, en la medida que contiene la capacidad de establecer actos jurídicos vinculantes. ${ }^{3}$ El orden eco-

3 Nota: "El Parlamento Europeo, elegido por sufragio universal, libre, directo y secreto, el Consejo Europeo y el Consejo, órganos intergubernamentales, la Comisión Europea, colegio independiente de carácter supranacional, y el Tribunal de Justicia, al que pueden acceder no solo los Estados y las instituciones sino también las personas fisicas y jurídicas, son cinco de esos siete órganos principales de esta organización internacional que constituye un fenómeno único en el mundo producto de la transferencia de competencias soberanas por parte de los Estados miembros" (Casado Raigón, 2017, p. 60). Dentro de su estructura destaca el Consejo de Europa (1949), cuya finalidad (Art.1 de su Estatuto) consiste en realizar una unión más estrecha entre sus miembros para salvaguardar y promover los ideales y los principios que constitu- 
nómico internacional aparece, por tanto, fragmentado desde el momento de la fundación de las Naciones Unidas, en paralelo a un orden militar internacional que ha acompañado a la geopolítica global que tiene su máximo reflejo en el estado de paz relativa que comporta la llamada Guerra Fría (1947-1991) y el posterior proceso de instauración de un orden económico capitalista globalizado.

En segundo lugar, una cuestión complementaria. ¿Existe un orden económico internacional? Existe, desde un punto de vista jurídico, un modelo económico internacional que es el resultado de un proceso histórico en continua evolución cuyo efecto es desigual. Entre los años 1946 y 1947, a través del Consejo Económico y Social de las Naciones Unidas, se crea el Acuerdo General sobre Aranceles Aduaneros y Comercio (GATT), y se promueve el proyecto de la creación de una Organización Internacional del Comercio como un organismo especializado de las Naciones Unidas, pero no se llega a constituir. En su lugar, se produce un proceso de implementación paulatina de un orden internacional económico que, en 1995, confluye en la fundación de la Organización Mundial del Comercio (омC), siendo un ente con vocación de universalidad que no ha sido vinculada formalmente a las Naciones Unidas, del mismo modo que ha sucedido con la Agencia Internacional de Energía Atómica (AIEA) (Pastor Ridruejo, p. 843). Desde su origen, se integran en la OMC los países del denominado bloque capitalista y, en el año 2013, se incorporan a dicha institución Rusia y China. En este contexto, en un orden internacional con notables contrastes de intereses

yen su patrimonio común y favorecer su progreso económico y social.

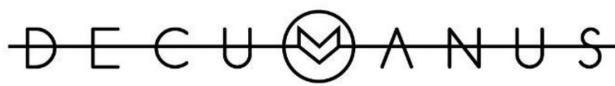

REVISTA INTERDISCIPLINARIA SOBRE ESTUDIOS URBANOS en los ámbitos económico, geoestratégico y militar, aparecen organizaciones regionales internacionales de marcado carácter económico que, por lo general, auspician mayores ventajas competitivas $y$, en definitiva, compiten entre sí.

En el campo económico, o preferentemente económico, es donde se sitúa, como decimos, la mayoría de las organizaciones particulares existentes. Baste citar, entre otras, la Organización de Cooperación y Desarrollo Económicos (OCDE), con sede en París; la Comunidad Andina, con sede en Lima; el Mercado Común del Sur (Mercosur), con sede en Montevideo; el Tratado de Libre Comercio de América del Norte (Nafta), que establece una zona de libre comercio entre Estados Unidos, México y Canadá; la Comunidad Económica Africana, con sede en Addis Abeba, o la Organización de Cooperación Económica Asia-Pacífico. Junto a ellas, y entre otras, encontramos organizaciones de cooperación preferentemente militar, caso de la Organización del Tratado del Atlántico Norte (otAN), con sede en Bruselas; el antiguo Pacto de Varsovia o de la Organización de Seguridad y Asistencia entre Australia, Nueva Zelanda y Estados Unidos. (Casado Raigón, pp. 60-61)

Asimismo, en un espacio sin un claro control político y social, el orden económico configura, paralelamente, la aparición de un espacio informal.

Novedad del mayor interés en el mundo globalizado de los inicios del siglo XXI es la aparición de grupos informales de Estados que, sin ser or- 
ganizaciones internacionales en sentido propio y situándose más allá de los lindes del Derecho Internacional, actúan como auténticos foros de consulta y cooperación, particularmente en terrenos tan importantes como la economía y el sistema financiero internacional. Un importante ente de esas características es el llamado G-20 (Pastor Ridruejo, p. 19).

Según el relato jurídico, resultado de un proceso histórico se concluye que se ha establecido una organización internacional de los Estados, en el que los poderes económicos han encontrado canales para su desarrollo a través de los derechos concedidos por ellos. Sin embargo, siendo estrictos, según los juristas citados (Pastor Ridruejo; Casado Raigón) no se puede considerar que exista una verdadera "sociedad interestatal" (Pastor Ridruejo, p. 87) ni un verdadero "constitucionalismo internacional" en la Carta de las Naciones Unidas (pp. 30-31). O, dicho de otro modo, pese a existir un determinado orden, "La sociedad internacional contemporánea también está afectada por una división en función del distinto poder político" (Casado Raigón, p. 70). Tanto Pastor Ridruejo como Casado Raigón identifican esta situación con un orden internacional basado en Estados soberanos que aparece en Europa con motivo del descubrimiento de América y se moderniza con la Paz de Westfalia (en 1648), pero que pese a los avances sociales que representan las Naciones Unidas mantiene su vigor. Dicho proceso es denominado "Sistema de Estado Civilizados" (Casado Raigón, p. 28), en el que el derecho internacional se centra en cuestiones políticas o en la guerra y la paz, y se concibe como un "derecho internacional clásico", situándose en convivencia con un "derecho internacional contemporáneo" que recoge el ideal de las Naciones Unidas. El derecho contemporáneo, en contraposición al clásico, implica "el respeto al principio de la igualdad de derechos y al de la libre determinación de los pueblos" (Pastor Ridruejo, p. 278), para el "fomento integral de los individuos y pueblos sin excepción alguna" (p. 273), mientras que el derecho clásico es heredero de la "expansión colonial y el imperialismo" (p. 273). En un sentido complementario, se identifica una tendencia a la institucionalización del orden internacional, junto a un proceso de humanización y socialización que tiene su reflejo en el derecho internacional contemporáneo, mientras que por otro lado se identifica la presencia de la fuerte inercia de un derecho internacional clásico en competencia, liberal, descentralizado y oligocrático (Casado Raigón, p. 37).

El derecho internacional engloba, pues, una compleja diversidad de significados, como la guerra y la paz, la civilización y la colonización, entre otros. El debate común -observable en la vida cotidiana y en los debates públicosconvive con esta realidad, argumentado que se trata de un proceso imperfecto del orden internacional, en el que coexisten valores y derechos históricos, que se debe y se puede corregir. La dinámica de las Naciones Unidas (2016; 2017) y las narrativas de los grandes poderes que se expresan en esta organización apuntan a esta dirección. Asimismo, la implementación de un escenario global marcado por un orden económico internacional variable, según Harvey (2014), forma parte de un desarrollo geográfico 
desigual que es necesariamente estructural. Es decir, que forma parte de los principios geográficos (Harvey, 2012. pp. 131-154) necesarios para la reproducción del capital acumulativo o, dicho de otro modo, que requiere la supervivencia del capitalismo.

Para comprender el encaje de este orden político, jurídico y económico internacional desigual, se identifica la secuencia de unos acuerdos internacionales que, a lo largo de la segunda mitad del siglo XX, confluyen en un escenario global en competencia. Dicha secuencia expone el proceso de implementación de un flujo de capital en circulación sin precedentes y con unas consecuencias sociales, ecológicas y ambientales evidentes, derivadas de la inestabilidad que genera el "libre uso" de las personas y los recursos para su explotación. Su patrón continuo es el constante incremento del capital circulante y la reproducción de su acumulación desigual. La secuencia de acuerdos es, a partir de las Naciones Unidas en 1945 (que incluye el Fondo Monetario Internacional y el Banco Mundial), el Derecho de Tratados de la Convención de Viena en 1969, la Carta de Derechos y Deberes Económicos de los Estados de 1974, que establece el programa para un Nuevo Orden Económico Internacional, y la Declaración sobre el Derecho al Desarrollo de 1986, que preceden a la creación de una Organización Mundial del Comercio desubicada de las Naciones Unidas en $1995 .^{4}$

4 La Convención de Viena sobre el Derecho de Tratados se formaliza el 23 de mayo de 1969 y entra en vigencia el 27 de enero de 1980, tras quince años de trabajo de la Comisión de Derecho Internacional de las Naciones Unidas; la Carta de Derechos y Deberes Económicos de los Estados se formaliza en la Resolución 3.281 (XXIX) de la Asamblea General del 12 de diciembre de 1974; y la Declaración

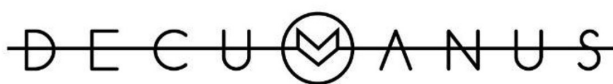

REVISTA INTERDISCIPLINARIA SOBRE ESTUDIOS URBANOS
Tal y como destaca Ahmed Mahiou (Naciones Unidas, 2011, p. 3): “El derecho internacional descansa sobre dos principios que constituyen su pedestal: la igualdad y la soberanía; estos principios abstractos y formalistas ocultan las situaciones reales muy desiguales de los Estados". Ante esta dicotomía, "el nuevo orden económico internacional cuestiona el postulado de la igualdad jurídica abstracta oponiéndolo a las situaciones reales y objetivas que muestran que los Estados no desempeñan la misma función en la sociedad internacional" (p. 3). Mahiou se refiere a la Carta de Derechos y Deberes Económicos de los Estados de 1974, que se postula entre la redacción y la vigencia efectiva del Derecho de Tratados (años 1969 y 1980). En ella se promueve un "nuevo orden económico internacional" que implica la revisión del derecho internacional clásico, cuyo principal baluarte es "El refuerzo de la ayuda internacional bilateral y multilateral en favor de la industrialización de los países en desarrollo" (párrafo 4 de la Declaración sobre el Establecimiento de un Nuevo Orden Económico Internacional) (Naciones Unidas, 2011, p. 3). Bajo esta premisa, junto con la libertad de los Estados de elegir "La libre gestión de sus recursos naturales y de las demás actividades económicas necesarias para el desarrollo y el control de las sociedades transnacionales" (incluida también en el párrafo 4) (p. 3), el llamado tercer mundo deposita sus esperanzas en el establecimiento de un nuevo orden más justo y equitativo, y le da su apoyo. Sin embargo,

sobre el Derecho al Desarrollo se formaliza en la Resolución 41/128 de la Asamblea General del 4 de diciembre de 1986. 
[...] durante la década de 1980, los países en desarrollo no lograron hacer prevalecer el reconocimiento del derecho al desarrollo (resolución 41/128, de 4 de diciembre de 1986), que habría podido dotar al nuevo orden económico internacional del fundamento jurídico que le faltaba; del mismo modo, tampoco lograron obtener un sistema internacional de control de la actividad de las sociedades transnacionales (Naciones Unidas, 2011, p. 5).

En su lugar, se inicia un nuevo estadio en competencia en múltiples alianzas regionales a escala internacional, junto con una flexibilización financiera que implica la introducción de nuevas reglas para facilitar el desarrollo (Naciones Unidas, 2011, p. 5). De este modo, se impone un escenario flexible apto para la libre competencia de las grandes corporaciones empresariales, así como una flexibilización financiera a escala global que fomenta el traslado de la industria a los paises en desarrollo, liberaliza la explotación de los recursos y (parafraseando a Harvey) se impone una lógica renovada para un desarrollo geográfico desigual que permite el estímulo de nuevas plusvalías para la dinamización económica del régimen capitalista. La flexibilización beneficia a los sectores financiero y empresarial, que ven ampliada la expansión de sus negocios mediante el desarrollo de nuevas áreas de mercado y oportunidades para la explotación (más recursos naturales y menos costes laborales). Les estructuras estatales, a su vez, desarrollan nuevas políticas para la captación de capitales y los territorios se adaptan a la transformación social que todo ello conlleva. Con el inicio de la industrialización globali- zada de los sistemas de producción, que implica el abandono del monopolio del proceso de manufactura por parte de los países desarrollados, el proceso de urbanización de la actividad humana inicia su etapa más expansiva (WWF, 2016).

En una economía globalizada que impone el patrón del crecimiento acumulativo, con una alza exponencial del capital que se ve reforzada a su vez por el desarrollo de las tecnologías de la información, el relato neoliberal abandona su retórica ideológica tradicional para introducirse en una narrativa esencialmente técnica y pragmática.

Con una renuncia substancial de la intención de buscar una solución efectiva y global a la desigualdad económica y social, se impone un orden económico internacional en competencia que permite el diseño y programación de grandes planes y programas para el desarrollo territorial, que se justifica por sí mismo como un bien colectivo. Los Estados renuncian al control de las sociedades transnacionales, se adaptan a ellas con la vocación de beneficiarse del plusvalor que generan (en lugar de ponerlas a su servicio) por la ausencia de un gobierno mundial efectivo que racionalice el estímulo indiscriminado de la competencia por el bien común o por el bien planetario. Esta situación tiene su impacto en las desigualdades observables en las grandes aglomeraciones urbanas que genera, en la sobreabundancia de recursos, por un lado, y la notable carencia, por el otro, que se crean, ejemplificado desde múltiples perspectivas.

El impacto de la normalización de una economía globalizada en competencia en el debate público es notorio, e introduce su propio lenguaje o narrativa. El progresivo proceso de regulación de 
un modelo o régimen económico acumulativo tiene su reflejo en el concepto de desarrollo urbanístico sostenible o sustentable, que se ha introducido en el marco legal urbanístico de referencia en las ciudades europeas (por ejemplo, la Ley de urbanismo catalana, de 2010 [Decreto legislativo nㅇ1, 2010]). Las contradicciones que ello implica, en lo referente a las tendencias globales al sobreconsumo y las desigualdades estructurales, cuya principal evidencia es el estilo de vida cosmopolita y una urbanización sistemática del espacio sin una planificación conjunta, no forman parte del debate legal instaurado. En el marco legal internacional, visible en el texto de los tratados de carácter económico (por ejemplo, el Tratado Constitutivo de la Comunidad Económica Europea, de 1957), el concepto de desarrollo se escenifica bajo la dinámica del estímulo de la competencia, que aspira a una mayor capacidad de obtención de plusvalías a través de la flexibilización y ampliación constante del proceso de producción y consumo. En esta esfera conceptual, la premisa fundamental del desarrollo es económica y traslada su función social a los Estados, en la medida que son ellos quienes tutelan y gestionan los derechos sociales de los ciudadanos (como se detalla en la Carta de los Derechos Fundamentales de la Unión Europea, de 2000). Por esta razón, el concepto de desarrollo económico y social se introduce en las constituciones estatales, dejando la cuestión de la competencia a la supeditación a los tratados o acuerdos internacionales. A su vez, emerge un lenguaje social renovado, con una conciencia global, que observa las contradicciones de un modelo imperfecto, siendo una evolución narrativa de un debate que, a mediados del siglo XX, fue internacional.

\section{Desarrollo práctico: la institucionalización del orden económico internacional en la gestión urbana de la metrópolis barcelonesa}

El contraste entre las aportaciones que realizan Harvey (2014) y Casellas (2016), junto con el análisis jurídico del Derecho Internacional y el rol de la economía globalizada, permite explorar el constante reequilibrio entre la presión que ejerce un modelo productivo expansivo con un impacto inestable y desigual y la reacción de las sociedades organizadas. Los cambios observados tienden a configurar una organización del modelo a escala internacional, mientras que las sociedades mantienen su control a través de los Estados, que basan la dinámica común del desarrollo en un comercio global que lejos de mitigar las desigualdades económicas lo que impone es su explotación. El estímulo del plusvalor por razones políticas, económicas y financieras, con o sin función social, crea, destruye y reconstruye escenarios para su reproducción, mientras crea infravalor a su alrededor, a costa de los recursos, las sociedades y de una inestabilidad estructural, como patrón sistémico de un modelo acumulativo exponencial. El modo en que este constructo económico se empodera de la gestión de una ciudad, como ocurre en el caso de Barcelona, se describe a continuación. 
El análisis del proceso de institucionalización de los poderes políticos, económicos y sociales -primero en el Estado español y luego en la metrópolis barcelonesa- requiere de una sistematización que permita comprender su evolución sin desviarse en el sendero de la descripción detallada de los acontecimientos. En esta línea, a través de un análisis circular se desarrollan los dos estadios de análisis del caso práctico que nos ocupa, en los que se contrasta la tendencia al control político y social de la ciudad en paralelo al control del sector económico del orden internacional a través de los Estados.

\subsection{Desarrollo práctico (I): el contraste entre la evolución del orden estatal e internacional institucionalizado y el proceso de regulación del orden legal urbanístico de aplicación en Barcelona}

El orden legal urbanístico incorpora en su articulado la regulación del plusvalor generado por la actividad planificadora y el uso racional de los recursos como justificación de un sistema económico global. En el caso del Estado español, el recorrido histórico del proceso de institucionalización de este orden territorial expresa la tendencia conjunta hacia la normalización de un orden regulado y su consecuente proceso de descentralización de las competencias. La gestión urbana metropolitana de Barcelona es, en este sentido, su última etapa visible, en la que los poderes económicos aparecen en ella de un modo público y notable, y la sociedad civil organizada participa, aunque de un modo re-

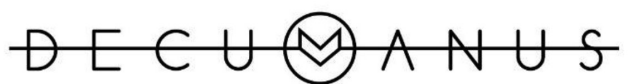

REVISTA INTERDISCIPLINARIA SOBRE ESTUDIOS URBANOS activo, del debate urbanístico. En este recorrido, a medida que la institucionalización del control del territorio se refuerza con un escenario político y económico favorable para su desarrollo, se observa una mejora en sus resultados, así como un avance de los derechos sociales que justifica la función pública del urbanismo.

El proceso de regulación del estímulo de la competencia en Europa Occidental, en el que el Estado español se introduce en una segunda instancia (en 1986), participa de un proceso de organización internacional y regional que solo es posible tras las I y II guerras mundiales (1914-1945), y en el caso particular de España, tras la Guerra Civil (1936-1939). De este modo, coincidiendo con el fin de la dictadura en 1975 y la implementación de un sistema democrático en España el 1978, confluye la tendencia global a la flexibilización de la economía y el abandono parcial del desarrollismo de Estado que caracteriza la reorganización que se impone tras las guerras mundiales. De este modo, se observa una relación entre el hecho de que Barcelona sea elegida como sede olimpica el 17 de octubre de 1986 y el ingreso de España en la Comunidad Económica Europea el 1 de enero de 1986, después de haber ingresado en la Organización del Tratado del Atlántico Norte (u OTAN) en 1982, integrándose así en el proyecto que confluirá en la Unión Europea en 1993, diseñada para dotar de una mayor competencia a la economía europea (occidental) en un nuevo escenario u orden económico internacional. ${ }^{5}$

5 Las principales etapas que muestran este proceso se reflejan en la siguiente secuencia de acontecimientos: 1936-1939 - Guerra Civil Española e inicio de una dictadura militar; 1939-1945 - II Guerra Mun- 
Tres etapas principales caracterizan el proceso de control estatal de la economía productiva en España hacia su posterior liberalización en una economía globalizada (años 1940-1995), que se resumen en:

- 1940-1978. Alianza político-económica tras una guerra y una reorganización internacional, que confluye en la creación del mayor conglomerado empresarial de España, el Instituto Nacional de Industria (o INI).

- 1978-1986. Apertura del Estado español a un sistema democrático que incorpora la función social en sus pilares de desarrollo, representando una capitalización económica y organizativa del Estado que repercute en una mayor dotación de recursos técnicos y financieros para el desarrollo colectivo. Primer desmantelamiento organizado del INI.

dial; 1945 - Fondo Monetario Internacional (FMI); 1947 - Plan Marshall; 1948 - Organización Europea para la Cooperación Económica (OECE); 1949 - Organización del Tratado del Atlántico Norte (OTAN); 1953 - Pactos de Madrid (España y los Estados Unidos de América pactan la instalación de bases militares en España, hecho que representa la incorporación de España en el bloque capitalista y la apertura a un proyecto de desarrollo económico internacional); 1955 - España ingresa en la OECE y en la ONU; 1957 - Comunidad Económica Europea (CEE); 1958 España ingresa en el FMI; 1960 - Organización para la Cooperación y el Desarrollo Económicos (OCDE); 1969 - Derecho de Tratados de la Convención de Viena; 1974 - Programa de acción sobre el establecimiento de un nuevo orden económico internacional; 1975 - Fin de la dictadura militar en España; 1982 - España ingresa en la OTAN; 1986 - Declaración sobre el derecho al desarrollo (que implica la pérdida de control internacional del derecho al desarrollo del Tercer Mundo en beneficio de las sociedades transnacionales); 1986 - España ingresa en la CEE; 1993 - Unión Europea (UE); 1995 - Organización Mundial del Comercio (OMC); 1995 - Euro (moneda única en la Unión Europea).

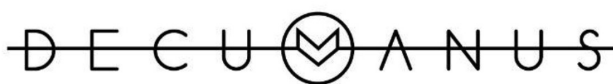

REVISTA INTERDISCIPLINARIA SOBRE ESTUDIOS URBANOS
- 1986-1995. Liberalización de la economía nacional al mercado internacional, tanto dentro de la Comunidad Económica Europea como hacia una economía globalizada, que confluye en la privatización definitiva del conglomerado empresarial nacionalizado estatal (la creación de la Sociedad Estatal de Participaciones Industriales [o SEPI], que pone fin al INI).

En este proceso, a partir del año 1977 se inicia un proceso de flexibilización del mercado laboral y del sector financiero, junto con una agrupación del sector empresarial. En 1977 se crea la Confederación Española de Organizaciones Empresariales (O CEOE), y en 1980 la Confederación Española de la Pequeña y Mediana Empresa (o CEPYME), así como la implementación de un sistema impositivo que permite la capitalización económica del Estado (en 1978 se crea el Impuesto de la Renta de las Personas Físicas y en 1986 el Impuesto del Valor Añadido, o IVA).

Por otro lado, el desarrollo del proceso de institucionalización efectiva de la función social de la gestión urbana en Barcelona sigue un proceso paralelo observable a través del marco legal urbanístico. Tras la Guerra Civil, con el mando del general Franco se inicia una nacionalización de la economía productiva (se implementan las bases del INI), que expulsa el capital internacional y dota al Estado de estructuras de control efectivo del desarrollo, pero con el aislamiento internacional. El proceso de descapitalización es notable, pero tras los acuerdos con los Estados Unidos de América en 1953 se inicia un proceso de regulación de la gestión del territorio que tiene su máximo exponente en la 
Ley de suelo de 1956 y en la creación del Ministerio de Vivienda en 1957, junto con la Dirección General de Vivienda y Urbanismo. En este contexto, entre los años 1959 y 1975 se diseñan y ejecutan tres planes de desarrollo conocidos como el Plan de Estabilización (1964-1967, Primer Plan de Desarrollo; 1968-1971, Segundo Plan de Desarrollo; y 1972-1975, Tercer Plan de Desarrollo). Esta coyuntura permite a España dotar a las ciudades de un nuevo impulso económico, en detrimento del sector agrario, que se ve obligado a abandonar en gran medida su modo de subsistencia tradicional, con un impacto territorial notable y múltiples deficiencias en el proceso de metropolitanización (o metropolización). Hasta el fin de la Dictadura (en 1975) no se normaliza el derecho de la ciudadanía a participar de la gestión urbana, del mismo modo que no es hasta entonces que se introduce la obligación efectiva de revertir el $10 \%$ de la plusvalía urbanística en vivienda pública o función social (Real Decreto, 1976). En 1990, este porcentaje se incrementa hasta el $15 \%$ (Ley de suelo, 1990) y, en paralelo a un proceso general de liberalización (y privatización) de los sectores económicos anteriormente nacionalizados, en 1994 se introduce el derecho de la competencia del agente urbanizador (Ley de urbanismo, 1994) y en 1998 se liberaliza el suelo urbanizable en toda España (Ley de suelo, 1998). De este modo se racionaliza y se hace más efectiva la función social de la gestión urbana, sin poder evitar por ello un proceso de especulación paralelo con unos resultados inciertos, tal y como describe en Barcelona Antònia Casellas (2016) y tal y como identifica a escala global David Harvey (2014). ${ }^{6}$

\subsection{Desarrollo práctico (II): el contraste entre la evolución del control ciudadano del territorio y el control político y económico asociado en el área metropolitana de Barcelona}

Debido a un pautado e intenso proceso de institucionalización que organiza y reorganiza los cambios que acontecen a escala global y estatal, a la vez que la implementación de un modelo económico expansivo normalizado se legalizan los derechos sociales y es posible la descentralización necesaria para una efectiva gestión urbana donde la ciudadanía esté representada. Paralelamente, tiene lugar un proceso equivalente de empoderamiento político y económico que, en el caso de Barcelona, confluye en una organización institucionalizada.

El control ciudadano de la ciudad presenta dos etapas previas al desarrollo de los procesos de participación ciudadana que el Ayuntamiento de Barcelona impulsa mediante unas normas reguladoras establecidas en 1986. En una primera etapa, tras el periodo de control militar que limita los derechos de expresión de la ciudadanía española, se produce una movilización social generalizada desde 1964 hasta 1978. En 1964 se regula el Derecho de Asociación (Ley no 191, 1964), y

6 Nota: la llamada "burbuja inmobiliaria" que tiene su impacto en España a partir de 2007 es un reflejo de esta flexibilización que tiene su naturaleza en el sector financiero, pero a su vez en el proyecto de un nuevo orden económico internacional que se diseña a partir de la década de 1970, como se indica en el Análisis conceptual II (apartado 2.2) de este artículo. 
en 1978 se aprueba la Constitución Española (CE), que instaura el sistema democrátic, en la forma de una monarquía parlamentaria (Artículo 1.3 de la CE). En esta culminación se reconoce el derecho de la ciudadanía a participar en los asuntos públicos, ${ }^{7}$ sin especificar cómo. Entre los años 1978 y 1985 se regula el derecho a participar, coincidiendo con una desmovilización social generalizada, hasta que se aprueba la Ley de Bases del Régimen Local (Ley no 7, 1985), en la cual se concluye que las asociaciones de vecinos no se consideran de utilidad pública (se limita así su derecho constitucional a participar en los asuntos públicos), y los Ayuntamientos se convierten en el máximo exponente de la representación ciudadana. Es a partir de este instante que el Ayuntamiento de Barcelona diseña los procesos participativos, otorgando a la ciudadanía una función reactiva en la gestión urbana (la ciudadanía interviene en la última etapa de la negociación de la planificación de la ciudad), mientras desarrolla y organiza la institucionalización formal del sector económico y empresarial, que adquiere notoriedad pública y una función activa en su desarrollo.

El control político de la gestión del territorio metropolitano de Barcelona presenta dos etapas principales, que permiten la transición a un sistema democrático y su posterior adaptación a un orden internacional que requiere de una organización supletoria. En una pri-

7 Nota: el Art. 23.1 de la Constitución Española indica que "Los ciudadanos tienen el derecho a participar en los asuntos públicos, directamente o por medio de representantes, libremente elegidos en elecciones periódicas por sufragio universal". El Art. 47, por otro lado, indica que "La comunidad participará en las plusvalías que genere la acción urbanística de los entes públicos".

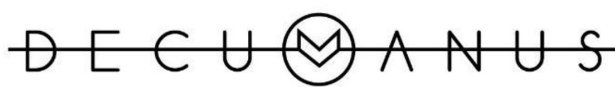

REVISTA INTERDISCIPLINARIA SOBRE ESTUDIOS URBANOS mera instancia se articula un organismo político en el ámbito metropolitano con el control subyacente del Estado, con la creación en 1974 de la Entidad Metropolitana de Barcelona (Decreto Legislativo no 5, 1974). En una segunda instancia, en 1987 se reorganiza la Organización territorial de la conurbación barcelonesa (Ley no 7, 1987), ${ }^{8}$ que permite la fundación del Plan Estratégico de Barcelona en 1988 (Ajuntament de Barcelona, 1990) y la paulatina regulación territorial de la administración regional de la Generalitat de Catalunya. A partir de este momento y hasta el 2010 se planifica el territorio catalán en su totalidad y se instaura un modelo de crear ciudad con la presencia formal del sector económico. Una vez que se concluye el proceso, se reintroduce el proyecto de un Área Metropolitana de Barcelona (Ley no 31,2010$)$ que promueve el diseño de un Plan Director Metropolitano con una marcada función estratégica en una economía globalizada.

El control económico de la metrópolis presenta dos etapas principales, paralelas a las que define el control político equivalente. En una primera etapa se identifica un proceso de negociación informal hasta 1988, para luego pasar a formar parte de un espacio de negociación formal a través el Plan Estratégico Económico y Social promovido por el Ayuntamiento de Barcelona. Dicho Plan evoluciona a lo largo del tiempo hasta adquirir una dimensión metropolitana

8 Nota: en 1987 se desmantela la Entidad Metropolitana de Barcelona creada en 1974 y se crean tres instituciones: 1) la Entidad Metropolitana del Transporte; 2) la Entidad Metropolitana de Medio Ambiente; y 3) la Mancomunidad de Municipios del Área Metropolitana. 
en 2003.9 Oficialmente, dicha entidad está representada por los agentes económicos y sociales del área metropolitana, pero técnicamente esta representación es desigual en su capacidad de influencia, en la medida que el capital inversor que atrae para el desarrollo de la ciudad es, principalmente, de naturaleza privada. De este modo, el Documento de Bases del último Plan Estratégico ${ }^{10}$ apuesta por: "La consolidación del 'Modelo Barcelona' que combina el crecimiento económico basado en los pilares de la nueva industria, la economía del conocimiento y las industrias creativas, con una metrópolis con un alto nivel de cohesión social" e incluye "La necesidad de incorporar en el nuevo proceso de reflexión estratégica, de una forma más intensa, las entidades e instituciones económico-sociales, especialmente las que forman parte del Consejo General", participando de este modo de una narrativa renovada que el proyecto neoliberal globalizado y desregulado (con una base social tutelada por el orden estatal e internacional clásico y contemporáneo) impone..1

9 Nota: etapas del Plan Estratégico: 1988 - Fundación Plan Estratégico Económico y Social (promovido por el Ayuntamiento de Barcelona, al margen del orden metropolitano); 1990 - Primer Plan Estratégico Económico y Social de Barcelona; 1994 Segundo Plan Estratégico de Barcelona; 1999 - Tercer Plan Estratégico de Barcelona; 2003 - Primer Plan Estratégico Metropolitano de Barcelona; 2007 - Revisión del Plan Estratégico Metropolitano; 2010 - Segundo Plan Estratégico Metropolitano de Barcelona (Visión 2020); 2014 - Tercer. Plan Estratégico Metropolitano de Barcelona (Horizonte 2025).

10 Fuente: http://www.pemb.cat/ca/projectes-estrategics/ [Consulta 7 de septiembre de 2016].

11 El Plan Estratégico Metropolitano de Barcelona (o PEMB) es una asociación privada sin ánimo de lucro -promovida por el Ayuntamiento de Barcelona y el Área Metropolitana de Barcelona- presidida por el presidente/a del Área Metropolitana de Barcelona (o AMB). El PEMB está integrado por

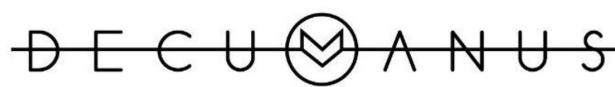

REVISTA INTERDISCIPLINARIA SOBRE ESTUDIOS URBANOS

\section{Debate y conclusiones}

El análisis transversal del análisis circular que ha caracterizado este artículo de investigación desarrolla dos debates principales que apuntan a un potencial desarrollo complementario.

Debate 1: El proceso de institucionalización geopolítica, económica y social en Barcelona está relacionado con dos tendencias comunes a toda colectividad humana: a) la incesante tendencia a la construcción sociocultural derivada de la geografía cambiante de su desarrollo; y b) la incesante tendencia al establecimiento de relaciones de poder por quienes dominan o protagonizan el pulso por el control de las ciudades y su dinamismo económico asociado. Ambas tendencias, en la medida que representan a intereses opuestos, pautan una relación conflictiva, pero en la medida en que se tienden a conciliar pautan unos intereses comunes para el beneficio mutuo. El caso del proceso de institucionalización de la gestión urbana en la metrópolis barcelonesa (a partir del ecuador del siglo XX) expresa el paso de la primera situación a la segunda, coincidiendo con

los principales agentes económicos y sociales del área metropolitana de Barcelona que, conjuntamente con el Ayuntamiento de Barcelona y el Área Metropolitana de Barcelona, son las siguientes instituciones promotoras: Aeropuerto de Barcelona; Cámara de Comercio de Barcelona; Círculo de Economía; Comisión Obrera Nacional de Cataluña; Consorcio de la Zona Franca; Feria de Barcelona; Fomento del Trabajo Nacional; Puerto de Barcelona; Unión General de Trabajadores; Universidad de Barcelona. Asimismo, en su Consejo General incorpora también a otras entidades económicas, sociales y culturales de la AMB que se han ido integrando en el tiempo y que forman parte del Consejo General. A nivel político, está representado por los treinta y seis municipios del área metropolitana de Barcelona y otras administraciones que operan en el territorio. 
la transición de un régimen estatal dictatorial a otro de democrático y social enmarcado en el proyecto de la Unión Europea. Se trata, por tanto, de una relación cómplice que participa de un reparto desigual del poder y de la riqueza siendo, por esta razón, una relación imperfecta que tiene su raíz en el encaje internacional de un constructo estatal en competencia que se mantiene a lo largo de los últimos siglos.

Debate 2: El proceso de institucionalización de la organización internacional, en el terreno económico, se ha desarrollado de un modo desigual y ha generado la presencia de una compleja organización económica informal. Esta situación permite el "juego de la competencia" a través de la desigualdad de derechos sociales que establece el dispar rol de los Estados en este constructo internacional, del mismo modo que permite la explotación intensiva y desigual de los recursos naturales sin un control social colectivo efectivo. Asimismo, resultado del contraste conjunto de los análisis conceptual y práctico, se constata la existencia de un paralelismo entre la economía informal organizada (pero no institucionalizada) y su reflejo en la ciudad informal de Barcelona, que se expande durante la dictadura militar (1936/1939-1975) y contrasta con otra más formal (institucionalizada) que caracteriza la metrópolis gestionada públicamente con la participación de los agentes económicos y sociales. Se trata, por tanto, de una relación causal que describe la diversidad de espacios que el capital encuentra para su actividad en las ciudades y en la medida que se introduce en un modelo institucionalizado dota a la ciudad de mayores prestaciones y de una mayor calidad de sus resultados, sin renunciar al factor especulativo de su carácter competitivo.

En conjunto, se constata una respuesta positiva al planteamiento de la hipótesis de trabajo al identificar el encaje geopolítico internacional del Estado español como condición necesaria para la implementación de una institucionalización formal del sector económico en la gestión urbana, que permite un empoderamiento político y social para su control. Asimismo, dicho empoderamiento es parcial en la medida que, tal y como se identifica en el análisis conceptual sobre el derecho internacional (apartado 2.2), el sector económico está exento de un control racional, debido a la ausencia de un empoderamiento político y social a escala global.

\section{Bibliografía citada}

Ajuntament de Barcelona (1990). Pla estratègic econòmic i social Barcelona 2000. Barcelona: autoedición.

Benach, N. (2014). Neoliberalismo y vida cotidiana en los márgenes urbanos. Revista Cidades, núm. 19, vol. 11, pp. 164-194. Sâo Paulo: Grupo de Estudios Urbanos.

Borja, J. (2010). Llums i ombres de l'urbanisme de Barcelona. Barcelona: Grup Editorial 62, Editorial Empúries.

Carta DFUE (2000). Carta de los Derechos Fundamentales de la Unión Europea. Parlamento Europeo, Consejo de la Unión Europea y Comisión Europea. Niza, 7 de diciembre de 2000.

Casado Raigón, R. (2017). Derecho internacional. Madrid: Editorial Tecnos (Grupo Anaya, S.A.).

Casellas, A. (2016). Desarrollo urbano, coaliciones de poder y participación ciudadana en Barcelona: una narrativa 
desde la geografia crítica. Boletín de la Asociación de Geógrafos Españoles, núm. 70, pp. 57-75. Madrid: Asociación de Geógrafos Españoles.

Comunidad Económica Europea (1957). Tratado Constitutivo de la Comunidad Económica Europea [Tratado de Roma]. Tratado celebrado y acordado en Roma el 25 de marzo de 1957, firmado por seis países (Bélgica, Alemania, Francia, Italia, Luxemburgo y los Países Bajos).

Consejo de Europa (1949). Estatuto del Consejo de Europa. Londres, a 5 de mayo de 1949.

Constitución Española (1978). Constitución Española. BOE núm. 311, de 29 de diciembre de 1978, pp. 29313-29424. Cortes Generales. España.

De Solà-Morales, M. (2008). Deu lliçons sobre Barcelona. Barcelona: Col-legi Oficial d'Arquitectes de Catalunya (COAC).

Decreto legislativo núm. 1 (2010). Decreto Legislativo 1/2010, de 3 de agosto, por el cual se aprueba el Texto refundido de la Ley de urbanismo. En el DOGC núm. 5686, de 5 de agosto de 2010. Departamento de la Presidencia, Generalitat de Catalunya. España.

Decreto legislativo núm. 5 (1974). Decreto-ley 5/1974, de 24 de agosto, por el que se crea la Entidad Municipal Metropolitana de Barcelona. En el BOE núm. 204, de 26 de agosto de 1974, pp. 1763017633. Jefatura del Estado. España.

Florida, R. (2009). Las ciudades creativas. Edición original en inglés, de 2007, titulada Who's your city. Barcelona: Paidós Ibérica.

Harvey, D. (2012). El enigma del capital y las crisis del capitalismo. Edición original en inglés de 2010, titulada The Enigma of Capital and de Crises of Capitalism. Madrid: Ediciones Akal.
---- (2014). “Desarrollos geográficos desiguales y producción de espacio". En Diecisiete contradicciones y el fin del capitalismo, pp. 149-164. Edición original en inglés, de 2014, titulada Seventeen Contradictions and de End of Capitalism. Quito: IAEN-Instituto de Altos Estudios Nacionales del Ecuador.

Ley de suelo (1956). Ley de 12 de mayo de 1956 sobre régimen del suelo y ordenación urbana. En el BOE núm. 135, de 14 de mayo de 1956, pp. 3106-3134. Jefatura del Estado. España.

---- (1990). Ley 8/1990, de 25 de julio, sobre Reforma del Régimen Urbanístico y Valoraciones del Suelo. BOE núm. 179, de 27 de julio de 1990, pp. 22060220173. Jefatura del Estado. España.

---- (1998). Ley 6/1998, de 13 de abril, sobre el régimen de suelo y valoraciones. BOE núm. 89, de 14 de abril de 1998, pp. 12296-12304. Jefatura del Estado. España. Ley de urbanismo (1994). Ley 6/1994, de 15 de noviembre de 1994, de la Generalitat Valenciana Reguladora de la Actividad Urbanística. BOE núm. 27, de 1 de febrero de 1995, p. 3099. Comunidad Valenciana. España.

Ley núm. 7 (1985). Ley 7/1985, de 2 de abril, reguladora de las Bases del Régimen Local. BOE núm. 80 , de 3 de abril de 1985, pp. 8945-8964. Jefe del Estado. España.

Ley núm. 7 (1987). Ley 7/1987, de 4 de abril, por la cual se establecen y regulan actuaciones públicas especiales en la conurbación de Barcelona y en las comarcas comprendidas dentro de su zona de influencia directa. DOGC núm. 826, de 8 de abril de 1987. Departamento de la Presidencia, Generalitat de Catalunya. España.

Ley núm. 31 (2010). Ley 31/2010, del 3 de agosto, del Área Metropolitana de Bar- 
celona. DOGC núm. 5708, de 6 de septiembre de 2010. Departamento de la Presidencia, Generalitat de Catalunya. España.

Ley núm. 191 (1964). Ley 191/1964, de 24 de diciembre, de Asociaciones. BOE núm. 311, de 28 de diciembre de 1964, pp. 17334-17336. Jefe del Estado. España.

Montaner, J. M. (2013). Arquitectura y crítica. Barcelona: Gustavo Gili.

ONU-Hábitat (2016). Urbanización y desarrollo: futuros emergentes. Reporte Ciudades del Mundo, 2016. Nairobi, Kenia: Programa de las Naciones Unidas para los Asentamientos Humanos, 2016.

Naciones Unidas (1945). Carta de les $\mathrm{Na}$ ciones Unidas. Conferencia de las $\mathrm{Na}-$ ciones Unidas sobre Organización Internacional. San Francisco, 26 de junio de 1945.

---- (1969). Derecho de Tratados. Convención de Viena de 23 de mayo de 1969.

---- (1974). Carta de Derechos y Deberes Económicos de los Estados. Resolución 3281 (XXIX) de la Asamblea General, de 12 de diciembre de 1974.

---- (1976). Declaración sobre los Asentamientos Humanos. Conferencia de las Naciones Unidas sobre los Asentamientos Humanos, celebrada en Vancouver (Canadá) entre los días 31 de mayo y 11 de junio de 1976.

---- (1986). Declaración sobre el derecho al desarrollo. Resolución 41/128 de la Asamblea General, de 4 de diciembre de 1986.

---- (1996). Declaración de Estambul sobre los Asentamientos Humanos. Conferencia de las Naciones Unidas sobre los Asentamientos Humanos, celebrada en Estambul (Turquía) entre los días 3 y 14 de junio de 1996.

---- (2011). La Declaración sobre el establecimiento de un nuevo orden eco- nómico internacional [por Ahmed Mahiou]. En la United Nations Audiovisual Library of International Law. En línea: http://www.un.org/law/avl/ [Consulta 16 de abril de 2018].

---- (2016). Declaración de Quito sobre ciudades y asentamientos humanos sostenibles para todos. Conferencia de las Naciones Unidas sobre la Vivienda y el Desarrollo Urbano Sostenible (Hábitat III), celebrada en Quito (Ecuador) entre los días 17 y 20 de octubre de 2016.

---- (2017). Nueva Agenda Urbana. Quito: autoedición. En línea: http://habitat3. org/wp-content/uploads/NUA-Spanish.pdf [Consulta 8 de marzo de 2018].

Normas Reguladoras de la Participación Ciudadana (1986). Normes Reguladores de la Participació Ciutadana. BOP núm. 121, de 21 mayo de 1986, pp. 27121. Generalitat de Catalunya. España.

Pastor Ridruejo, J. A. (2017). Curso de derecho internacional público y organizaciones internacionales. Madrid: Editorial Tecnos (Grupo Anaya, S.A.).

Real Decreto núm. 1346 (1976). Real Decreto $1346 / 1976$, de 9 de abril, por el que se aprueba el texto refundido de la Ley sobre Régimen del Suelo y Ordenación Urbana. BOE núm. 144, de 16 de junio de 1976, pp. 11755-11769. Ministerio de la Vivienda. España.

WWF (2016). Informe Planeta Vivo 2016. Riesgo y resiliencia en el Antropoceno. Glanz, Suiza: autoedición. En línea: http:/ /awsassets.wwf.es/downloads/ informeplanetavivo_2016.pdf [Consulta 3 de marzo de 2018]. 